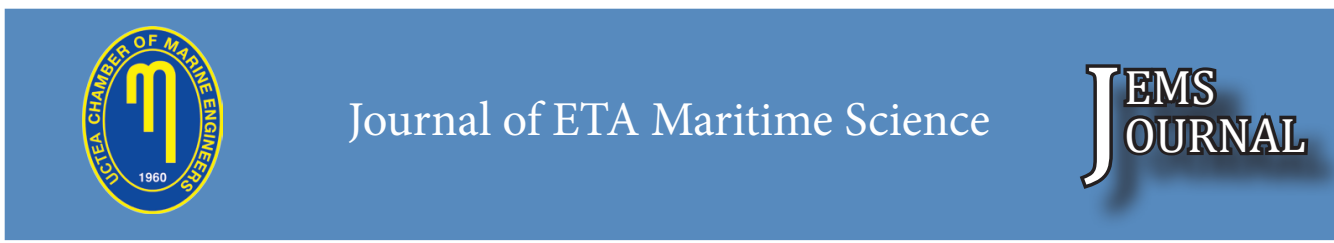

Corresponding Author: Ali DOĞRUL

\title{
Hydrodynamic Investigation of a Submarine Moving Under Free Surface
}

\section{Ali DOĞRUL}

Ylldız Technical University, Naval Architecture and Maritime Faculty, Turkey adogrul@yildiz.edu.tr; ORCID ID: https://orcid.org/0000-0003-3236-555X

\begin{abstract}
Submerged bodies are commonly used in many fields such as scientific researches, military and commercial applications. Especially in military applications, submarines have a significant role as a silent and deterrent vehicle. Contrary to popular belief, submerged bodies also operate in shallow depth that free surface effects come into play. This causes the visual identification of submarines while protecting them from sonar detection. This study focuses on the investigation of free surface effects on submarine hydrodynamics moving forward in different depths. The numerical calculations have been conducted at different Reynolds numbers ranging from $1.5 \times 10^{7}$ to $3.5 \times 10^{7}$ for both bare and appended forms of DARPA Suboff. A commercial CFD solver has been used to solve URANS equations with $k$-E turbulence model. The numerical approach has first been verified and validated with the available experimental data. Later, the numerical results have been discussed in terms of total resistance, resistance components and free surface deformations. It has been concluded that the submergence depth has a significant role on resistance components for depth Froude number larger than 0.7 and the appendages have little effect on free surface deformations in all depths.
\end{abstract}

Keywords: Appendage, CFD, DARPA, Free Surface, Resistance.

\section{Serbest Yüzey Altında İlerleyen Bir Denizaltının Hidrodinamik Açıdan İncelenmesi}

$\ddot{O} z$

Batmışcisimler araştırma, askerive ticariuygulamalargibipekçokalandayaygın birşsekilde kullanılmaktadır. Özellikle askeri uygulamalarda denizaltılar sessiz ve caydırıcı bir araç olarak önemli bir role sahiptir. Sanılanın aksine, batmıș cisimler serbest yüzey etkilerinin devreye girdiği sığ derinlikte de çalıșmaktadır. $\mathrm{Bu}$ durum denizaltıları sonar tespitinden korurken görsel olarak tespit edilmelerine sebep olmaktadır. Bu çalıșma farklı derinliklerde ilerleyen denizaltının hidrodinamiğine serbest yüzey etkilerinin incelenmesine odaklanmaktadır. Sayısal hesaplamalar $1.5 \times 10^{7}$ ile $3.5 \times 10^{7}$ arasindaki Reynolds sayılarında takıntısız ve

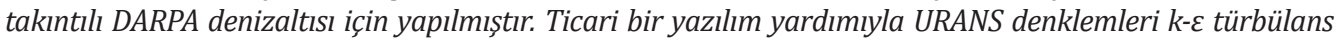
modeli kullanılarak çözülmüştür. Sayısal yöntem ilk önce eldeki deneysel veri ile doğrulanıp onaylanmıştır. Daha sonra sayısal sonuçlar, toplam direnç, direnç bileșenleri ve serbest yüzey deformasyonları açısından değerlendirilmiștir. Sonuç olarak derinlik Froude sayısının 0.7'den büyük olduğu durumlarda derinliğin dirence önemli bir etkisinin olduğu ve tüm derinliklerde takıntının serbest yüzey deformasyonuna etkisinin çok az olduğu görülmüştür.

Anahtar Kelimeler: Takıntı, HAD, DARPA, Serbest Yüzey, Direnç.

To cite this article: Doğrul, A. (2019). Hydrodynamic Investigation of a Submarine Moving Under Free Surface. Journal of ETA Maritime Science, 7(3) 


\section{Introduction}

Nowadays submerged bodies are widely used in various fields. Autonomous underwater vehicles (AUV) are preferred for scientific research in deep seas while swimmer delivery vehicles (SDV) are operated by navy seals for sneak operations. Modern navies contain submarines for several military operations. Another submerged body is the torpedo which is the lethal weapon of the naval battles. This is why researchers study submerged bodies in many aspects.

The prediction of the hydrodynamic performance of submerged bodies is crucial by means of total resistance and effective power. While doing this, it has to be considered that submerged bodies operate not only as totally submerged but also near free surface. Especially the naval submarines can operate near free surface because sonar detection becomes difficult near free surface. In addition, torpedoes operate near free surface because the draft of the target vessel is relatively small. Therefore, special attention has to be given to the submarine hydrodynamics when it is moving close to the free surface. Because the resistance components of a submerged body are similar to a surface ship when operating in shallow depths. The contribution of the resistance components on the total resistance depends on the hull geometry, velocity and proximity to the free surface [1].

In recent years, several studies have been made by researchers about submarine hydrodynamics. Some of them are based on resistance estimation while the rest are focused on self-propulsion characteristics of submerged bodies. A few studies have been made about submerged body hydrodynamics operating near free surface.

Fundamental studies for designing a benchmark submerged body have been made by Groves et al. [2]. They have described a mathematical formulation for DARPA Suboff form both for bare and appended cases. Huang et al. [3] and Liu et al. [4] have conducted several experiments in order to estimate the total resistance of DARPA Suboff model. Well-known DARPA Suboff bare hull (AFF-1) and appended hull (AFF-8) have been investigated by Chase in terms of total resistance and propeller performance both numerically and experimentally [5]. Chase and Carrica [6] have investigated DARPA Suboff AFF8 model in order to observe the selfpropulsion characteristics using INSEAN E1619 model propeller with a RANS solver. Posa et al. [7] have also investigated resistance and propulsion performance of DARPA Suboff model using different turbulence models. There are other studies on submerged body-propeller interaction by means of resistance components and propulsion characteristics [8-11].

The studies mentioned above are made for the condition that the submarine is totally submerged which means that the free surface effects are neglected. Few studies have been made for DARPA Suboff model operating in the depths which free surface effects are significant. Wilson-Haffenden et al. [12] have studied wavemaking resistance of a submarine travelling below the free surface. They have conducted towing experiments for bare form of DARPA Suboff (AFF-1) and calculated total resistance and resistance components such as frictional and residual resistance for different depths in shallow water condition. After that, they have compared the experimental results with CFD simulation results.

Dawson [13] have studied experimental and numerical investigation of submarine hydrodynamics for different velocities and depths. He has focused on the total resistance of Joubert conventional submarine and DARPA Suboff model. He has especially conducted experiments in near free surface depths and compared the results with numerical results based on 
potential flow theory.

Nematollahi et al. [14] have made a numerical investigation of an underwater vehicle (UWV) and searched the relation between submergence depth and total resistance for different velocities. They have also observed the wake structure behind the submerged body for different depths.

Vali et al. [15] have conducted resistance experiments for a model scale attack submarine in submergence and surface conditions. They have compared the experimental results with the numerical ones based on a RANS solver. They have also estimated the required power for all conditions.

Amiri et al. [16] have focused on the effect of shallow depth on submarine hydrodynamics using CFD method. They have conducted numerical analyses for DARPA Suboff AFF-1 bare form and compared the numerical results with the experimental data in terms of total resistance. They have calculated lift and moment coefficients of the submerged body for different depths.

A recent study has been made by Shariati et al. [17]. The authors have mentioned the significance of the detection of submerged bodies moving near free surface. They have proposed a procedure for the identification of underwater vehicles by observing the free surface deformations along the submerged body. They have estimated the vehicle's velocity and depth with the help of wavelength and wave amplitude.

In this paper, it is aimed to investigate the effect of submergence depth on total resistance, resistance components and free surface deformation of DARPA Suboff submarine model. Both AFF-1 and AFF8 models have been analyzed in order to show the effect of appendage on submarine hydrodynamics. The numerical analyses have been carried out for different depth Froude numbers that covers a depth range between sub-critical and super- critical conditions in terms of wave making resistance. RANS equations have been discretized using a commercial CFD solver with $\mathrm{k}-\varepsilon$ turbulence model. The numerical method has been verified for submerged condition with also modelling free surface. After that, the method has been validated with the available experimental data. It has been concluded that the submergence depth has a significant role on resistance components for depth Froude number larger than 0.7 and the appendages have little effect on free surface deformations in all depths.

\section{Mathematical Background}

\subsection{Governing Equations}

For incompressible and turbulent flows, the continuity equation and momentum equations are given in Cartesian coordinates as below:

$\frac{\partial U_{i}}{\partial x_{i}}=0$

$\frac{\partial U_{i}}{\partial t}+\frac{\partial\left(U_{i} U_{j}\right)}{\partial x_{j}}=-\frac{1}{\rho} \frac{\partial P}{\partial x_{i}}+\frac{\partial}{\partial x_{j}}\left[v\left(\frac{\partial U_{i}}{\partial x_{j}}+\frac{\partial U_{j}}{\partial x_{i}}\right)\right]-\frac{\partial \overline{u_{i}^{\prime} u_{j}^{\prime}}}{\partial x_{j}}$

Here, $\mathrm{P}$ is the mean pressure, $p$ the density and $v$ the kinematic viscosity of the fluid. $U_{i}$ velocity can be divided into two components; mean velocity and fluctuating, respectively.

$U_{i}=\overline{U_{i}}+u_{i}^{\prime}$

Turbulent flow around the submarine is simulated using $\mathrm{k}-\varepsilon$ turbulence model that is widely used in ship hydrodynamics field. The last term of the momentum equation is the Reynolds stress tensor, which is given below:

$\overline{u_{i} u_{j}^{\prime}}=-v_{t}\left(\frac{\partial U_{i}}{\partial x_{j}}+\frac{\partial U_{j}}{\partial x_{i}}\right)+\frac{2}{3} \delta_{i j} k$

Detailed information about the turbulence model can be found in Wilcox [18]. 


\subsection{Uncertainty Assessment}

Estimation of numerical uncertainty was first introduced by Richardson [19] for a dam stress problem. In recent years, several methods have been proposed by many researchers. Besides, Grid Convergence Index method has been recommended by ITTC [20] in ship hydrodynamics problems as a verification procedure. The GCI method was first proposed by Roache [21], later further developed by Celik et al. [22]. Numerical uncertainty is mainly caused by grid spacing, time step size and iteration [23].

In this study, the GCI method was employed to calculate the uncertainty for grid spacing. Background of the procedure is briefly explained below:

$$
r_{21}=\frac{h_{2}}{h_{1}} \quad r_{32}=\frac{h_{3}}{h_{2}}
$$

Refinement factor represents the ratio of two grid sets, which should be greater than 1.3 according to the method of Celik et al. [22]. The refinement factor has been chosen as $\sqrt{2}$ which is also used in recent studies [11, 24]. Three different cases having different grid numbers are created. In this case, refinement factors are calculated by proportioning the total grid numbers.

$$
r_{21}=\left(\frac{N_{1}}{N_{2}}\right)^{1 / 3} \quad r_{32}=\left(\frac{N_{2}}{N_{3}}\right)^{1 / 3}
$$

After checking the refinement factor, the difference between the numerical results is used for calculating the grid convergence condition (R).

$$
\begin{aligned}
& \varepsilon_{21}=X_{2}-X_{1} \quad \varepsilon_{32}=X_{3}-X_{2} \\
& R=\frac{\varepsilon_{21}}{\varepsilon_{32}}
\end{aligned}
$$

The value of $\mathrm{R}$ determines whether the solution is monotonically convergent
$(0<R<1)$ or it has an oscillating convergence $(-1<\mathrm{R}<0)$ [25].

\section{Numerical Method}

\subsection{Main Particulars}

DARPASuboff model submarine has been used as a benchmark case. The geometrical properties and the experimental resistance data can be found in the literature [2]-[4]. Figure 1 shows 3 -D view of the submarine models AFF- 1 and AFF-8. The geometrical properties of DARPA Suboff models can be seen in Table 1.

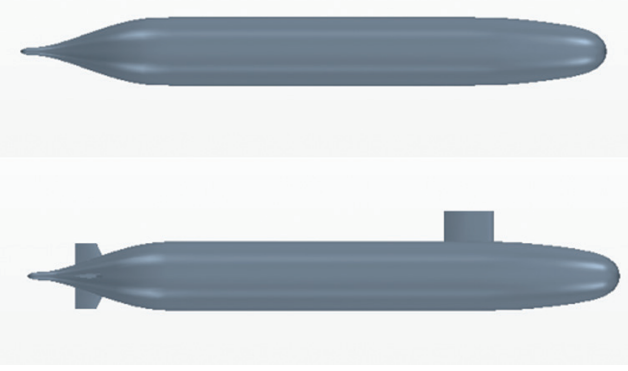

Figure 1. 3-D view of AFF-1 and AFF-8 submarine models

Table 1. Geometrical properties of DARPA Suboff [2]

\begin{tabular}{|l|c|c|}
\hline & AFF-1 & AFF-8 \\
\hline$\lambda$ & 24 & 24 \\
\hline $\mathrm{L}_{\mathrm{OA}}(\mathrm{m})$ & 4.356 & 4.356 \\
\hline $\mathrm{L}_{\mathrm{PP}}(\mathrm{m})$ & 4.261 & 4.261 \\
\hline $\mathrm{D}_{\max }(\mathrm{m})$ & 0.508 & 0.508 \\
\hline $\mathrm{S}\left(\mathrm{m}^{2}\right)$ & 5.989 & 6.348 \\
\hline$\nabla\left(\mathrm{m}^{3}\right)$ & 0.699 & 0.706 \\
\hline
\end{tabular}

\subsection{Mesh Generation}

According to the numerical method, the governing equations are discretized and solved via finite volume method. For this reason, a three dimensional computational domain has been created consisting of finite volume elements. Commercial CFD 
software STAR-CCM+ has been used for mesh generation and flow simulations. This software offers a trimmer mesh algorithm that provides fully hexahedral meshing in the computational domain.

Prism layers have been created near submarine hull in order to model the flow inside the boundary layer. Some mesh refinements in bow and stern regions have been created to represent the submarine hull surface precisely. In addition, denser mesh has been used in the wake zone for modeling the wake field in the downstream. Special care has been given to the mesh structure near and on the free surface. Mesh refinements have been made to well capture the free surface deformations. Local mesh refinements around the submarine hull can be seen in Figure 2 .

Figure 3 shows the wall $y+$ distribution on the surface of AFF-1 and AFF-8 geometries for $\mathrm{V}=3.0452 \mathrm{~m} / \mathrm{s}$ and 3.051 $\mathrm{m} / \mathrm{s}$ at depth Froude number of 0.7 . The wall $y+$ values are kept between 30-300.

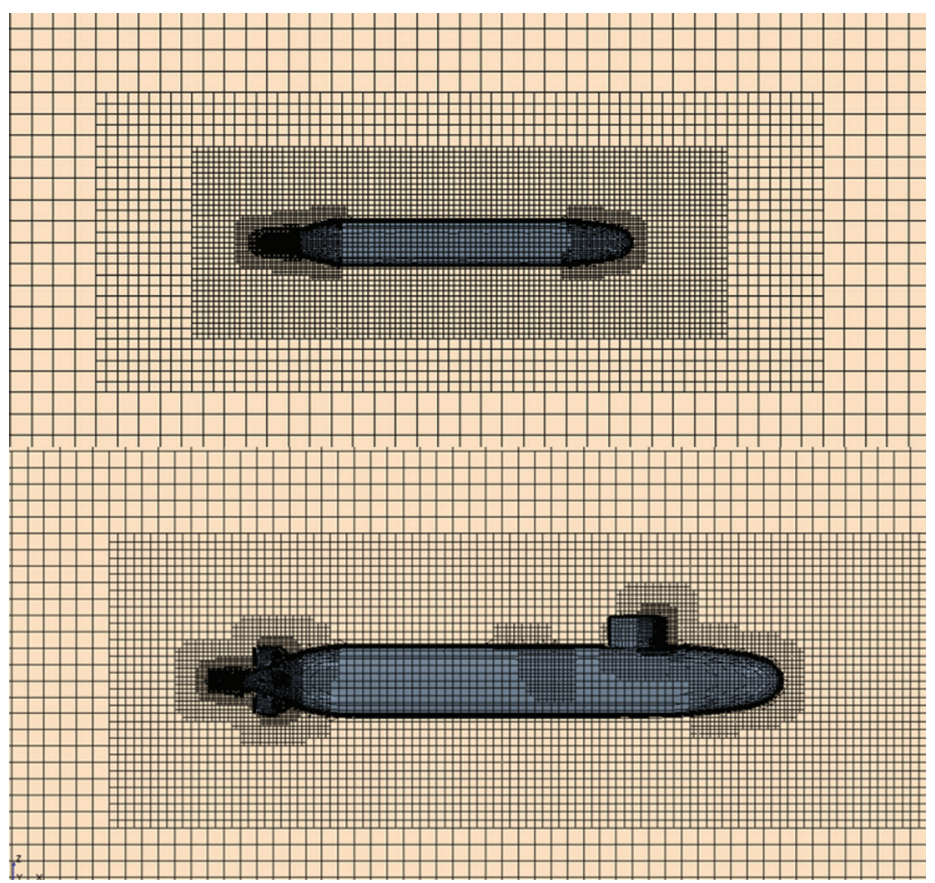

Figure 2. Mesh structure around the submarines (AFF-1 and AFF-8) from a cross-sectional view

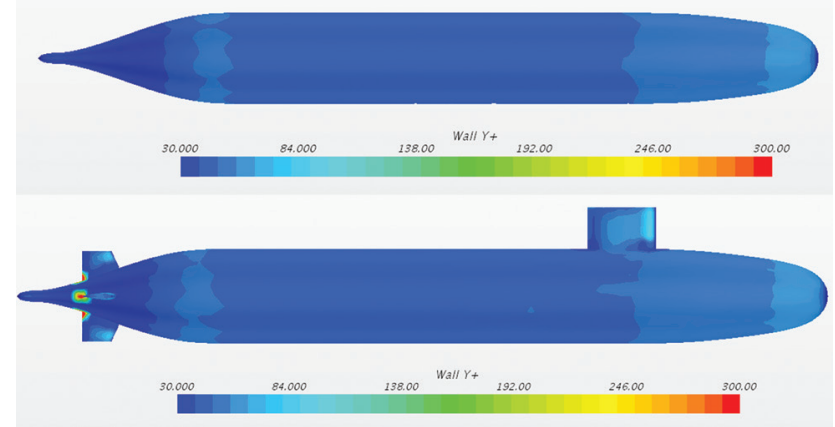

Figure 3. Wall $y+$ distribution on the surface of AFF-1 and AFF-8 geometries 


\subsection{Physics Modelling}

The dimensions of the computational domain and the boundary conditions applied on the surfaces are of great importance. The size of the domain has been determined in accordance with the recommended guideline of ITTC [26]. The distance in the upstream is $1.5 \mathrm{~L}_{\mathrm{pP}}$ while in downstream it is $5 \mathrm{~L}_{\mathrm{PP}}$. The distance in up and bottom directions are to be $2 \mathrm{~L}_{\mathrm{PP}}$ and the transverse distance is chosen as $2 \mathrm{~L}_{\mathrm{PP}}$.

Correctness of boundary conditions defines the accuracy of the numerical method and computational time needed for solution. Proper boundary conditions have been applied on the submarine and domain surfaces in order to eliminate the effect of the domain boundaries [27]. The surface in the positive $\mathrm{x}$ direction is defined as velocity inlet and the surface in the opposite direction is defined as pressure outlet. The surrounding surfaces are chosen as symmetry plane that dictates the normal component of the velocity is zero, so the wall effects from these surfaces can be eliminated. The submarine surface is defined as no-slip wall which means that all velocity components (so the total velocity) are to be zero. Figure 4 shows the computational domain and the boundary conditions applied on the surfaces. Detailed information about the boundary conditions can be found in the user guide of the CFD software [28].
In this study, turbulent flow around DARPA Suboff model has been solved using standard $\mathrm{k}-\varepsilon$ turbulence model, which has been widely used for ship hydrodynamics. Querard et al. [29] have stated that standard $\mathrm{k}-\varepsilon$ turbulence model is useful by means of computational time when compared with similar models. Standard k- $\varepsilon$ turbulence model has been used in many recent studies such as Liu et al. [30], Nematollahi et al. [14], Shariati et al. [31], Shariati et al. [17] and Sezen et al. [11].

To simulate the free surface flow of DARPA Suboff model, Volume of Fluid (VOF) method has been employed and a flat wave has been modeled at a desired depth. VOF method solves the position of the free surface instantly and calculates the volume fraction of each cell whether it is filled with water and/or air. In this study, the submarine model has been considered as submerged in all cases, however free surface effects are taken into account by using VOF method.

Since the simulations have been conducted in an unsteady manner, choice of time step is crucial for a time-effective analysis. For implicit unsteady simulations, ITTC [26] recommends the time step as $\Delta \mathrm{t}=0.005 \sim 0.01 \mathrm{~L} / \mathrm{U}$ for calm water resistance estimation, where $L$ is the ship length and $U$ is the ship speed. In this paper, time step size has been chosen as $\Delta t=0.015$ seconds that satisfies this recommendation.

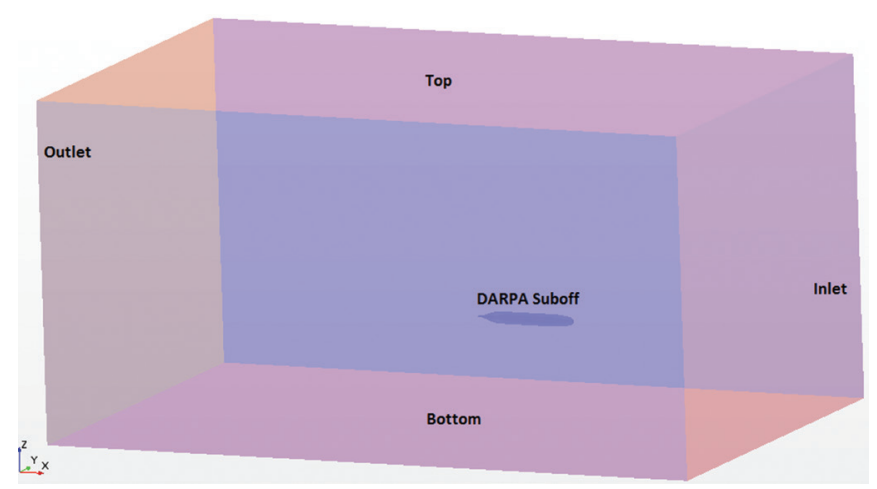

Figure 4. Computational domain and the boundary conditions 
Convergence of the analysis has been checked in terms of both numerical residual-time history and total resistance. The methodology followed is shown in Figure 5.

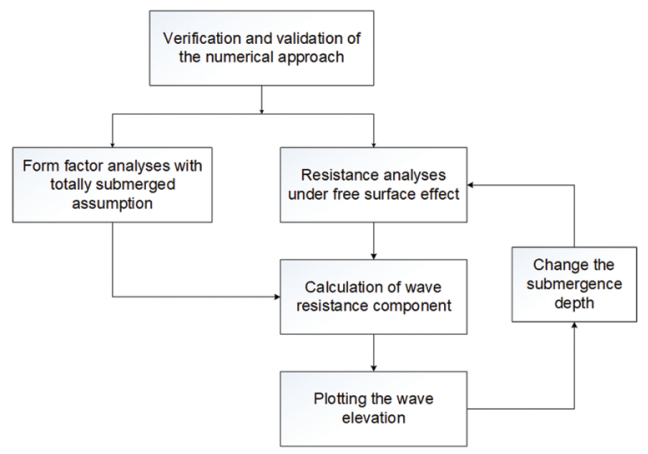

Figure 5. The methodology followed in this study

\section{Results and Discussions}

DARPA Suboff AFF-1 and AFF-8 models have been analyzed in totally submerged condition using different grid numbers. Verification study has been conducted to determine the optimum grid number for both geometries. Later, the numerical method has been validated with the available experimental data using the optimum grid number. Following these steps, the flow around submarine has been simulated at various depths and velocities to observe the effect of depth on resistance components and free surface deformations. In addition, appendage effect has been investigated.

\subsection{Verification and Validation}

An uncertainty study has been conducted for the verification of the numerical method used in this paper. Numerical uncertainty of grid number has been calculated by generating three different grid numbers by changing grid spacing with a proper refinement factor. Uncertainty for time step size has been done for three different time step size using fine grid number. Uncertainty value has been calculated with Grid Convergence Index (GCI) method [22] for both bare (AFF-1) and appended (AFF8 ) submarine models. Table 2 shows the generated grid numbers and time step sizes for the CFD method to be verified.

Table 2. Grid numbers and time step sizes used in uncertainty assessment

\begin{tabular}{|l|c|c|c|}
\hline Grid type & AFF-1 & AFF-8 & $\begin{array}{c}\text { Time step } \\
(\mathrm{s})\end{array}$ \\
\hline Fine & 383965 & 509267 & 0.015 \\
\hline Medium & 257379 & 335065 & 0.03 \\
\hline Coarse & 188460 & 256319 & 0.06 \\
\hline
\end{tabular}

The uncertainty study has been made for AFF-1 and AFF-8 forms for $\mathrm{V}=3.0452 \mathrm{~m} / \mathrm{s}$ and $V=3.051 \mathrm{~m} / \mathrm{s}$ at a depth Froude number of $0.7 \quad\left(\mathrm{Fn}_{\mathrm{h}}=0.7\right)$. Spatial (grid number) and temporal (time step) uncertainty analyses have been done using GCI method. According to the uncertainty analyses, fine mesh was chosen for both submarine models to be analyzed at various depths and velocities. Time step size was chosen as the fine one. The spatial uncertainty and convergence condition numbers are presented in Table 3. As can be seen from the table, grid structure for AFF-1 has an oscillating convergence while AFF-8 grid is monotonically convergent. Table 4 shows the temporal uncertainty and convergence condition numbers for AFF-1 and AFF-8 geometries. For both geometries, temporal uncertainty values are too low and the results show that both geometries have a monotonic convergence.

Table 3. Spatial uncertainty analyses for AFF-1 and AFF-8

\begin{tabular}{|l|c|c|}
\hline & AFF-1 & AFF-8 \\
\hline$\% \mathrm{GCI}_{\mathrm{FINE}}$ & 0.21 & 0.58 \\
\hline $\mathrm{R}$ (Convergence condition) & -0.415 & 0.342 \\
\hline
\end{tabular}

Table 4. Temporal uncertainty analyses for AFF-1 and AFF-8

\begin{tabular}{|l|c|c|}
\hline & AFF-1 & AFF-8 \\
\hline$\%$ GCI $_{\text {FINE }}$ & 0.002 & 0.008 \\
\hline R (Convergence condition) & 0.056 & 0.124 \\
\hline
\end{tabular}


The uncertainty study is made at $\mathrm{Fn}_{\mathrm{h}}=0.7$ because it is considered that there will be free surface effects at that depth. In addition to the uncertainty study under free surface effect, similar grid structure was used to simulate the flow around the submarine geometries at totally submerged. So the total resistance has been validated with available experimental data that was gained in totally submerged condition. With the help of the verification and validation study, the grid structure including free surface refinements has been verified and validated. Validation of CFD method with experimental data and the numerical results of the totally submerged condition in terms of total resistance can be seen in Table 5.

Table 5. Validation of CFD method for AFF-1 and AFF-8

\begin{tabular}{|l|c|c|}
\hline & AFF-1 & AFF-8 \\
\hline $\begin{array}{l}\text { Experiment } \\
\text { (Totally submerged) [N] }\end{array}$ & 87.40 & 102.30 \\
\hline CFD (Totally submerged) [N] & 86.47 & 104.70 \\
\hline
\end{tabular}

\subsection{Resistance Analyses}

In order to calculate the total resistance and resistance components, the validation study is expanded for more ship velocities of which experimental results exist. For the calculation of wave resistance component, several analyses are conducted in totally submerged condition to calculate the form factor of the hull in each velocity. With the help of the form factor, wave resistance could be estimated for each ship. Figures 6 and 7 show the comparison of the numerical results of DARPA Suboff AFF-1 and AFF-8 with the available experimental results [4] and another numerical study [11].

Here, the total resistance consists of frictional resistance and viscous pressure resistance because the submarine is considered as totally submerged. By using the ITTC formula [32] for frictional resistance component, the form factor can

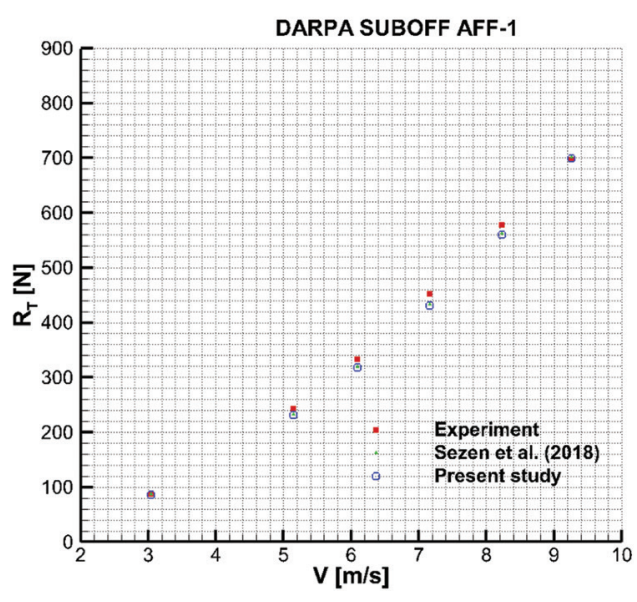

Figure 6. Comparison of total resistance for DARPA Suboff AFF-1

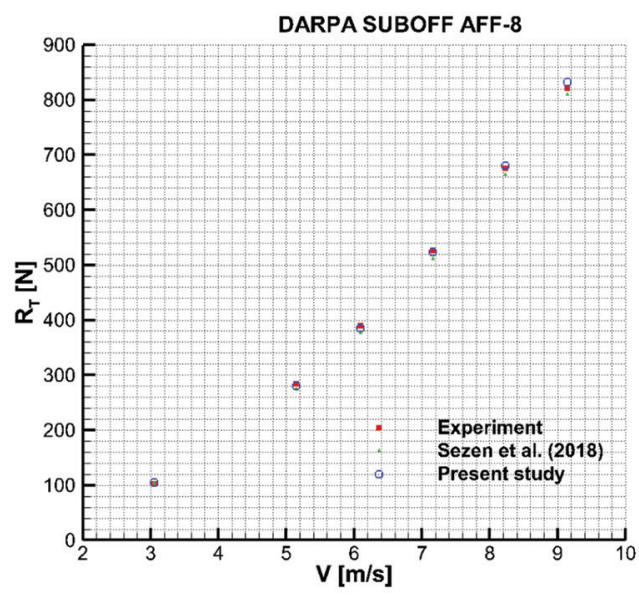

Figure 7. Comparison of total resistance for DARPA Suboff AFF-8

be derived at each velocity. The resistance components under free surface can be discretized as below [33]:

$$
\begin{aligned}
& \mathrm{R}_{\mathrm{T}}=\mathrm{R}_{\mathrm{F}}+\mathrm{R}_{\mathrm{VP}} \\
& C_{F}=\frac{0.075}{(\log R n-2)^{2}} \\
& R_{F}=0.5 \cdot \rho \cdot S \cdot V^{2} \cdot C_{F} \\
& k=\frac{R_{V P}}{R_{F}}
\end{aligned}
$$


Figure 8 presents the calculated form factor for both bare hull (AFF-1) and appended hull (AFF-8). The rudders and the sail in AFF- 8 model almost double the form factor, which influences the wave resistance component.

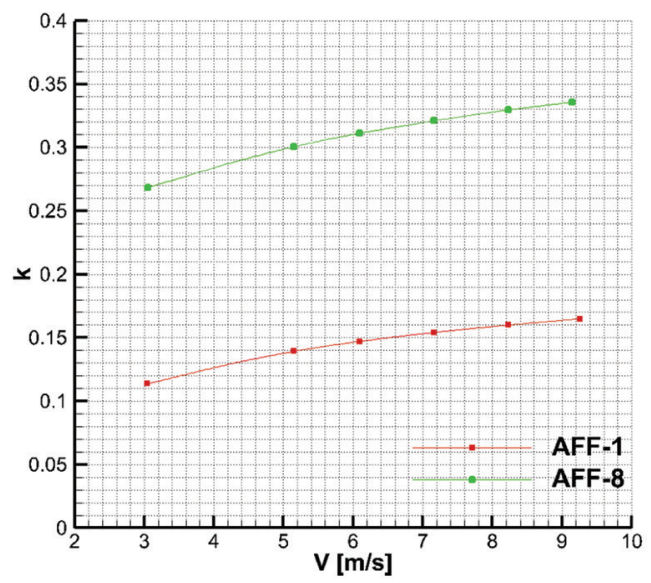

Figure 8. Form factor calculation for AFF-1 and AFF-8

\subsection{Free Surface Pattern}

Behaviour of the total resistance at different depth Froude numbers are given in Figure 9. Depth Froude number is calculated as follows:

$$
F n_{h}=\frac{V}{\sqrt{g \cdot h}}
$$

Here, $\mathrm{V}$ is the submarine velocity, $h$ is the depth between the submarine centerline and the free surface level, and $g$ is the acceleration of gravity which is taken as $9.81 \mathrm{~m} / \mathrm{s}^{2}$.

As can be seen from Figure 9, at slow speed, free surface affects the total resistance significantly, especially after a certain depth $\left(\mathrm{Fn}_{\mathrm{h}}=0.7\right)$. The total resistance stays nearly the same at high speeds while the submergence depth increases. This behaviour is valid also for appended case. Figure 10 shows the wave resistance component for AFF-1 and AFF8 submarine forms. The wave resistance component was calculated using the form factor at each velocity and submergence depth. As expected, only at slow speed, the wave resistance component rises with the increase in depth, so the total resistance also increases. Figure 11 shows the change on non-dimensional wave resistance coefficient with length Froude number (Fn) at different depths.

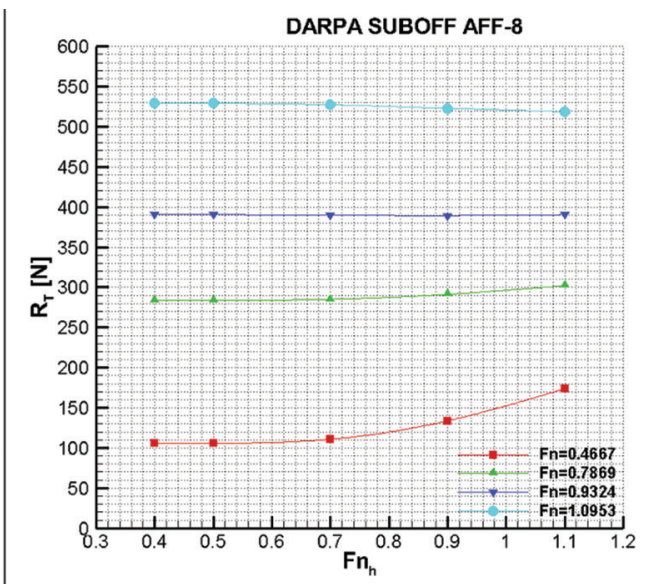

Figure 9. Total resistance of AFF-1 and AFF-8 at different depths 

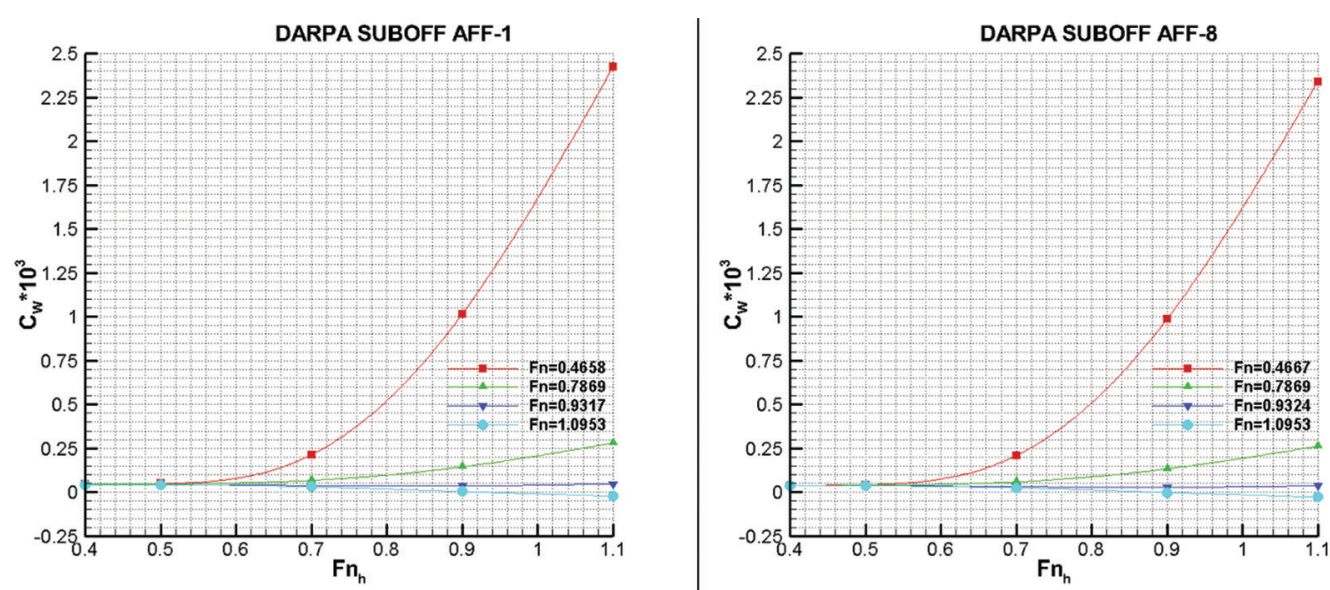

Figure 10. Wave resistance coefficient of AFF-1 and AFF-8 at different depths
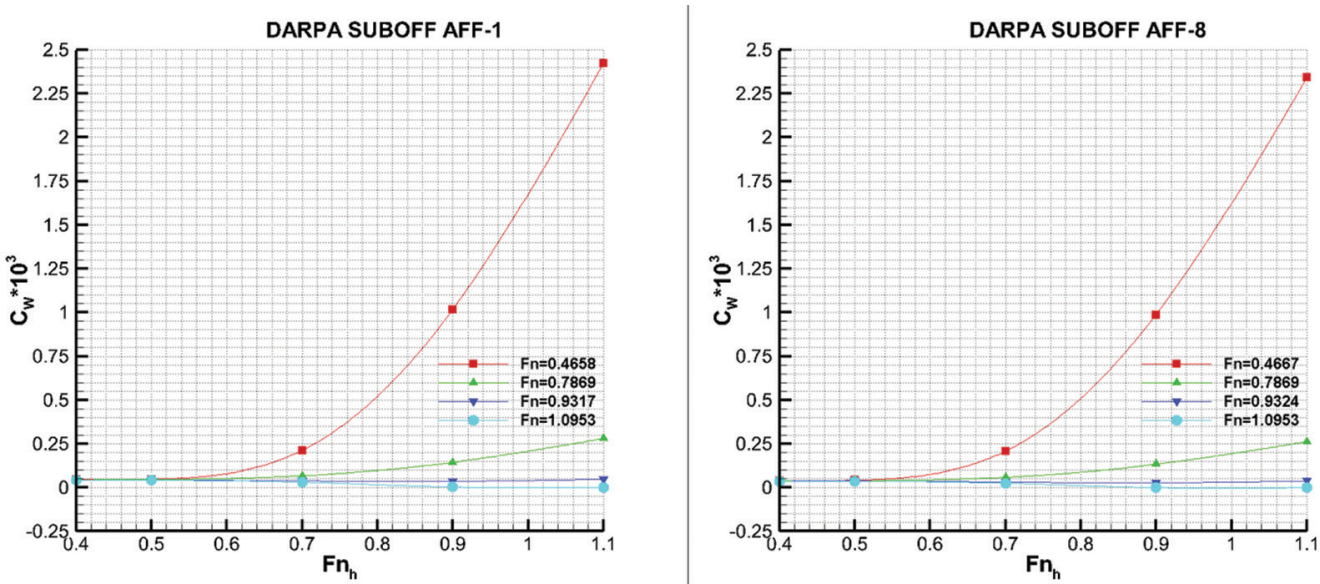

Figure 11. Wave resistance coefficient of AFF-1 and AFF-8 at various submarine velocities

Figure 12 shows the wave elevation contours on the free water surface at depth Froude number of 0.7 as sample cases. Detailed wave elevation results for each velocity and depth are given in the figures below.

Figure 13 and 14 show the free surface deformations in the submarine centerline level for low and high velocities, respectively. Figure 9 gives the wave profiles at $\mathrm{V}=3.0452$ $\mathrm{m} / \mathrm{s}$ for AFF-1 and V=3.051 m/s for AFF-8. It can be seen that the free surface starts to deform after Fnh=0.5 that leads to an increase in total resistance of AFF-1 and AFF-8 models. Figure 14 represents the relation between wave elevation and depth Froude number for AFF-1 and AFF-8 models at $V=7.1604 \mathrm{~m} / \mathrm{s}$. Figure 14 shows that the free surface deformation slightly changes for high depth Froude numbers which means little increase in wave resistance and total resistance. Both figures also show that the appendages have nearly no effect on wave elevation for all submarine velocities.

One may see the free surface deformations for different velocities along the hull centerline in Figure 15. The free surface starts to deform with the increase in submarine velocity as expected. The wave crest shifts to the submarine stern in 


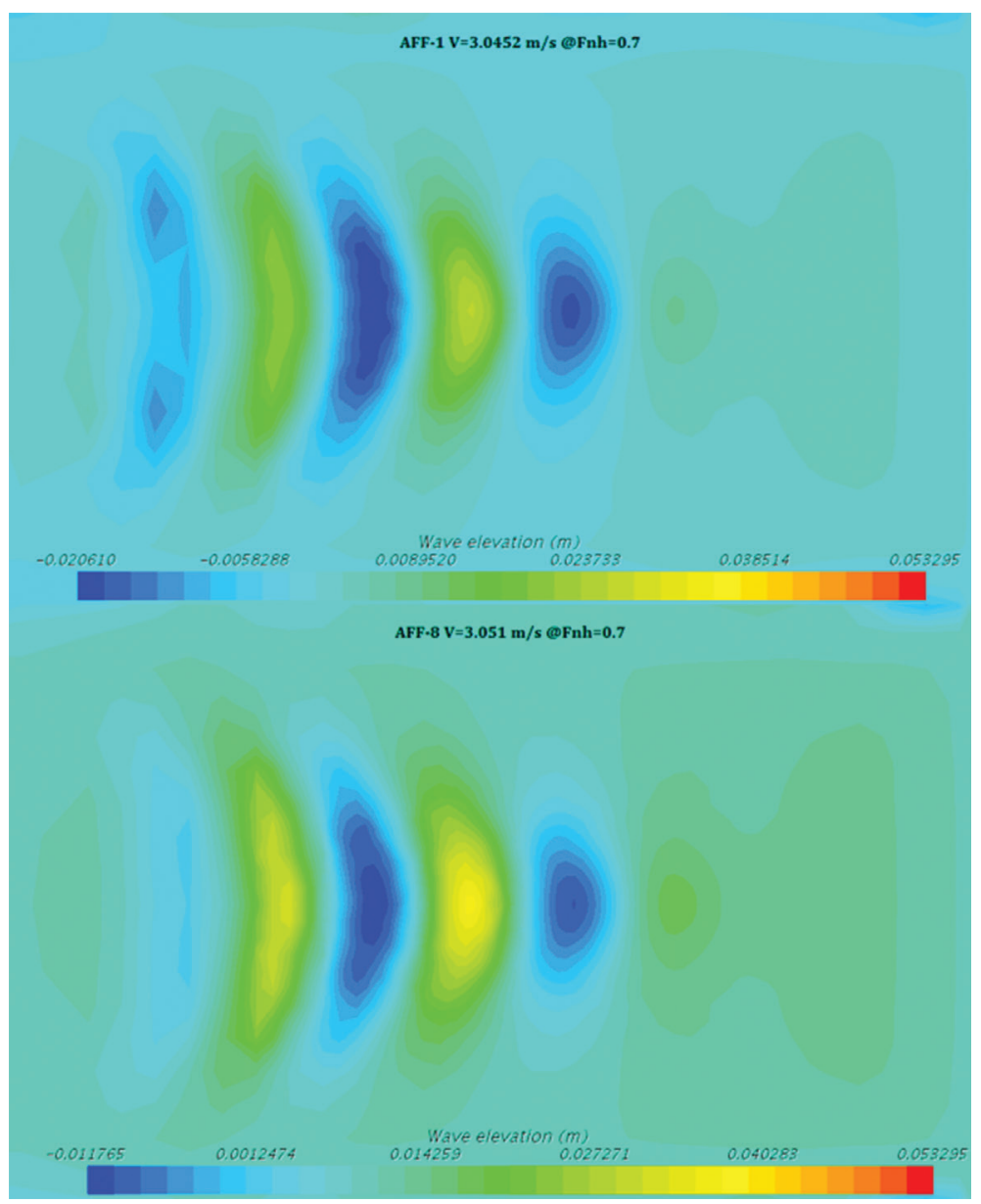

Figure 12. Wave contours of AFF-1 and AFF-8 for $V=3.0452 \mathrm{~m} / \mathrm{s}$ and $3.051 \mathrm{~m} / \mathrm{s}$ at $F n_{h}=0.7$

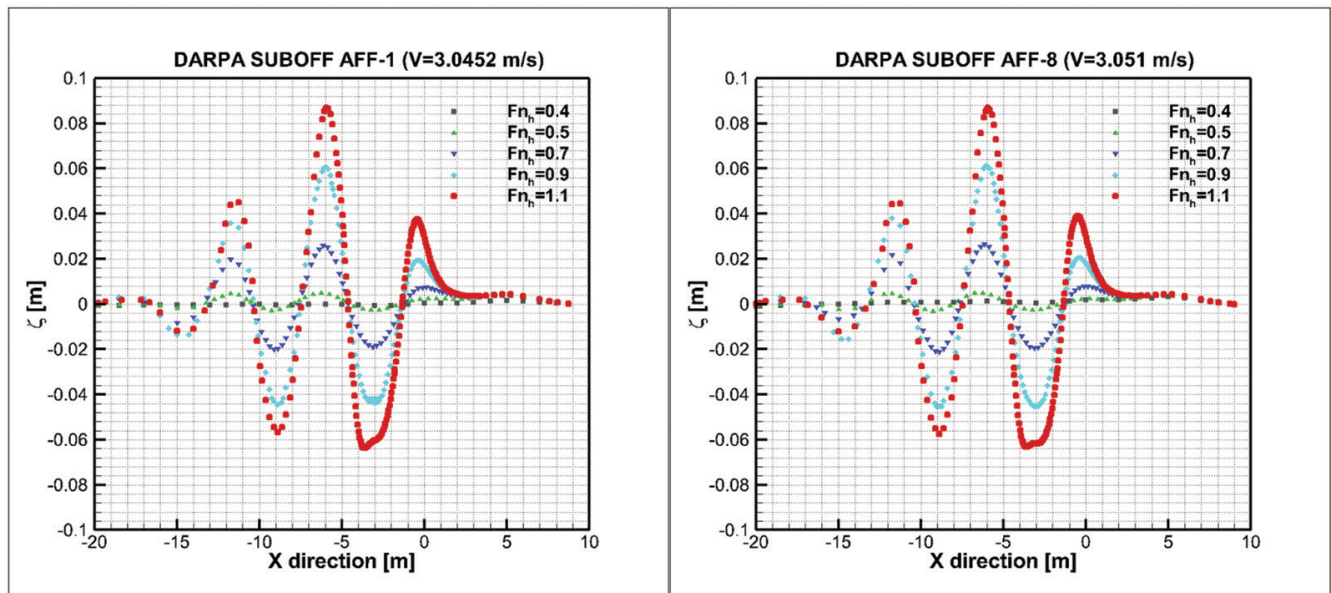

Figure 13. Wave profile of AFF-1 and AFF-8 at $V=3.0452 \mathrm{~m} / \mathrm{s}$ and $3.051 \mathrm{~m} / \mathrm{s}$ 


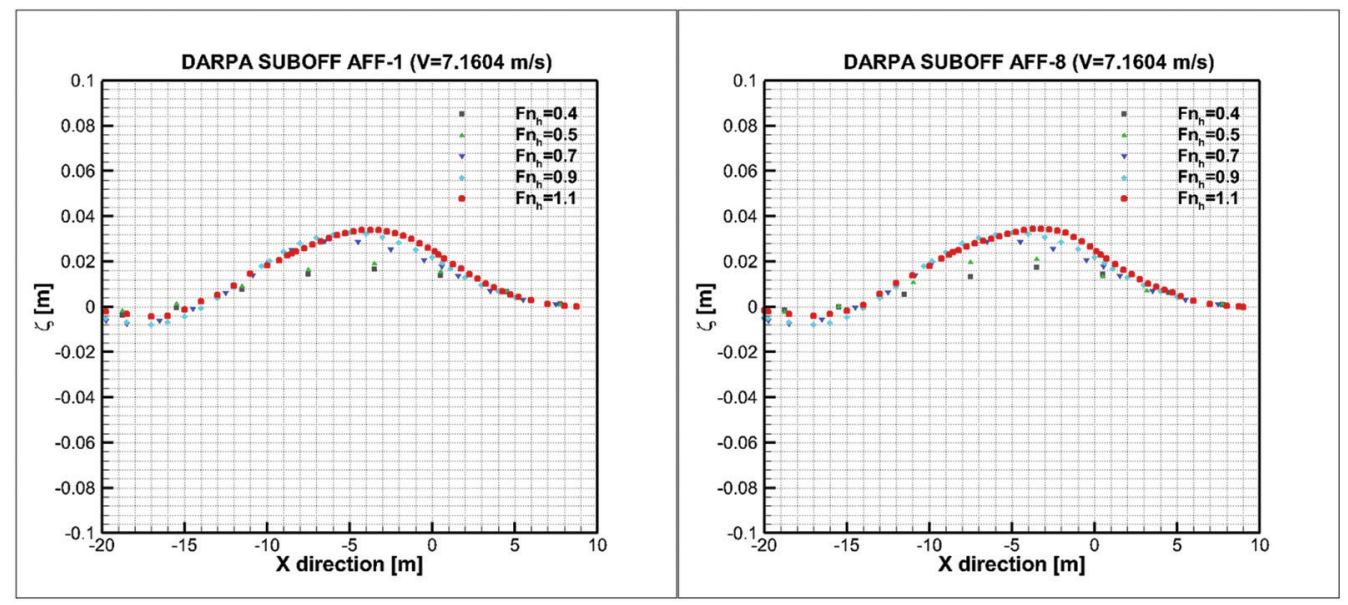

Figure 14. Wave profile of AFF-1 and $A F F-8$ at $V=7.1604 \mathrm{~m} / \mathrm{s}$

high speeds in both depth Froude numbers (Fnh=0.4 and 1.1). With the increase in depth Froude number, wavelength shows a decrease while the position of the wave crest remains nearly same at slow velocity $(\mathrm{V}=3.051 \mathrm{~m} / \mathrm{s})$ that causes a significant rise in wave resistance and total resistance.

The results show that the contribution of wave resistance on the total resistance is higher at lower velocities when the submarine is very close to the free surface. So, the wave energy is higher which means higher wave heights. Because the energy carried by the waves is directly proportional with the square of the wave height.

\section{Conclusion}

This study focuses on the numerical prediction of hydrodynamic performance of a benchmark submarine model moving forward under free surface. Different submergence depths and ship velocities were investigated for both bare and appended submarine models. Effect of submergence depth and appendage on resistance components and wave elevation were studied for various ship velocities numerically.

The numerical method discretizing RANS equations were used which were verified and validated with the GCI method.

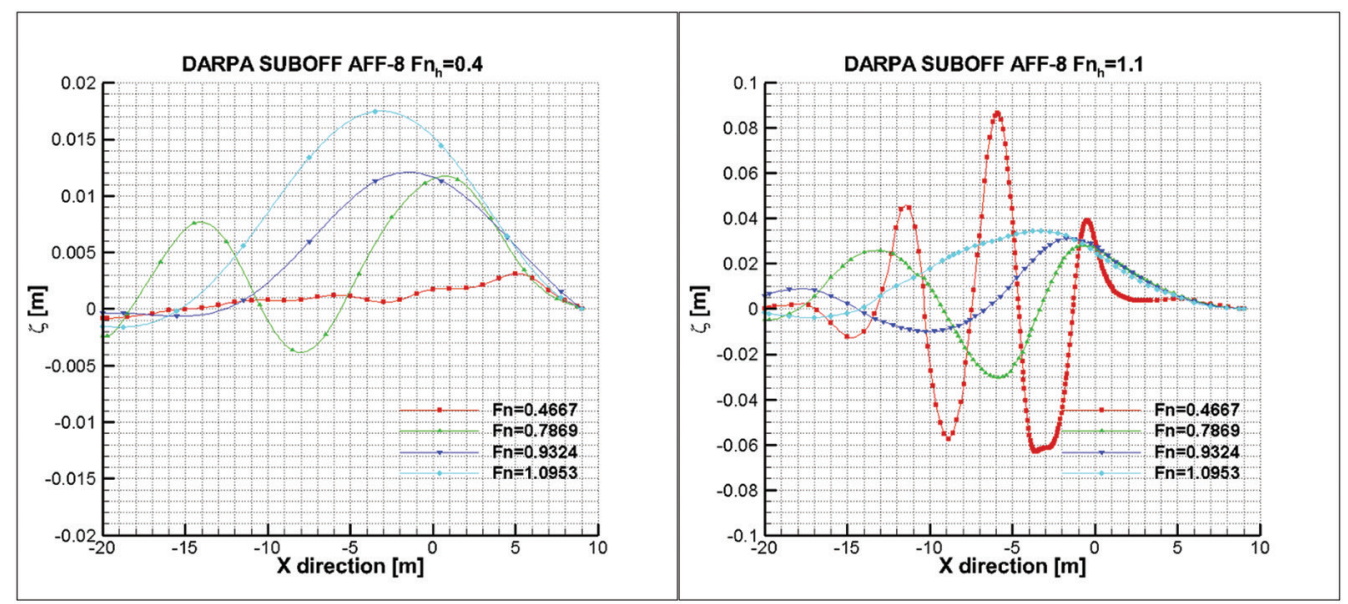

Figure 15. Wave profile of $A F F-8$ at $F n_{h}=0.4$ (left) and 1.1 (right) for different velocities 
The numerical results have been in good agreement with the available experimental data. Submergence depth was seen to change in a wide range including shallow depths that causes visual detection of the submarine under free surface.

For the cases in which depth Froude number is lower than 0.7 , the submarine behaves like totally submerged that neglects the free surface effects. After $\mathrm{Fn}_{\mathrm{h}}=0.7$, free surface starts to be significant. In this case, free surface deformations can be observed clearly and total resistance shows an increase.

For slow speed $(\mathrm{V}=3.051 \mathrm{~m} / \mathrm{s})$, wave deformations change drastically while the submarine moves near free surface. This leads to a significant increase in total resistance and wave resistance of the submarine for both bare (AFF-1) and appended (AFF-8) geometries.

For high speeds ( $>3.051 \mathrm{~m} / \mathrm{s})$, submarine total resistance remain nearly constant with the change in submergence depth. This means that the wave resistance remains constant at all depths.

Form factor of the model submarine was calculated with the analyses at totally submerged case. After that, wave resistance of the submarine at various cases were derived using the form factor. It is observed that the submarine appendages (sail and rudder fins) nearly double the form factor. However, the increase in the form factor and the viscous pressure compensates the increase in total resistance. Therefore, the wave resistance remains nearly constant in bare and appended submarine models.

Because of lack of experimental data in submarine hydrodynamics field, CFD can be used widely for parametric prediction of submarine hydrodynamics. Self-propulsion characteristics and motion response under free surface effects can be investigated numerically.

As a future work, self-propulsion characteristics of submerged bodies will be investigated under free surface effects. In addition, different appendage designs and configurations can be studied in terms of resistance and nominal wake field.

\section{Nomenclature}

\begin{tabular}{|l|l|}
\hline $\bar{U}_{i}$ & mean velocity component \\
\hline$u_{i}{ }^{\prime}$ & fluctuation velocity component \\
\hline $\mathrm{P}$ & mean pressure \\
\hline$\rho$ & fluid density \\
\hline $\mathrm{k}$ & turbulent kinetic energy \\
\hline$\varepsilon$ & turbulent dissipation rate \\
\hline $\mathrm{R}$ & convergence condition \\
\hline$\lambda$ & scale factor \\
\hline $\mathrm{L}_{\mathrm{OA}}$ & length overall \\
\hline $\mathrm{L}_{\mathrm{PP}}$ & length between perpendiculars \\
\hline $\mathrm{Dmax}$ & submarine maximum diameter \\
\hline $\mathrm{S}$ & submarine wetted surface area \\
\hline$\nabla$ & submarine displacement \\
\hline $\mathrm{V}$ & submarine velocity \\
\hline $\mathrm{R}_{\mathrm{T}}$ & total resistance \\
\hline $\mathrm{R}_{\mathrm{F}}$ & friction resistance \\
\hline $\mathrm{R}_{\mathrm{VP}}$ & viscous pressure resistance \\
\hline $\mathrm{C}_{\mathrm{F}}$ & $\begin{array}{l}\text { non-dimensional friction } \\
\text { resistance coefficient }\end{array}$ \\
\hline $\mathrm{k}$ & form factor \\
\hline $\mathrm{h}$ & submarine depth \\
\hline $\mathrm{Fn}$ & depth Froude number \\
\hline $\mathrm{Fn}$ & length Froude number \\
\hline $\mathrm{C}_{\mathrm{W}}$ & $\begin{array}{l}\text { non-dimensional wave } \\
\text { resistance coefficient }\end{array}$ \\
\hline $\mathrm{Fn}$ & Froude number \\
\hline & wave elevation \\
\hline
\end{tabular}




\section{References}

[1] M.

Renilson,

Submarine Hydrodynamics. Springer International Publishing, 2015.

[2] N. C. Groves, T. T. Huang, and M. S. Chang, "Geometric characteristics of DARPA SUBOFF models (DTRC Model Nos. 5470 and 5471)," DTRC/ SHD-1298-01, 1989.

[3] T.Huangand H.L.Liu, "Measurements of flows over an axisymmetric body with various appendages in a wind tunnel: the DARPA SUBOFF experimental program," presented at the 19th Symposium on Naval Hydrodynamics, Seoul, South Korea, 1994.

[4] H.-L. Liu and T. T. Huang, "Summary of DARPA Suboff Experimental Program Data," Naval Surface Warfare Center Carderock Division (NSWCCD), West Bethesda, MD, USA, CRDKNSWC/HD-1298-11, 1998.

[5] N. Chase, "Simulations of the DARPA Suboff submarine including self-propulsion with the E1619 propeller," Master Thesis, University of Iowa, 2012.

[6] N. Chase and P. M. Carrica, "Submarine propeller computations and application to self-propulsion of DARPA Suboff," Ocean Eng., vol. 60, pp. 68-80, Mar. 2013.

[7] A. Posa and E. Balaras, "Large-Eddy simulations of a notional submarine in towed and self-propelled configurations," Comput. Fluids, vol. 165, pp. 116-126, Mar. 2018.

[8] A. B. Philips, S. R. Turnock, and M. Furlong, "Comparisons of CFD simulations and in-service data for the self-propelled performance of an autonomous underwater vehicle," presented at the 27th Symposium on Naval Hydrodynamics, Seoul, Korea, 2008.
[9] N. Zhang and S. Zhang, "Numerical simulation of hull/propeller interaction of submarine in submergence and near surface conditions," J. Hydrodyn. Ser B, vol. 26, no. 1, pp. 50-56, Feb. 2014.

[10] A. Dogrul, S. Sezen, C. Delen, and S. Bal, "Self-Propulsion Simulation of DARPA Suboff," presented at the International Maritime Association of the Mediterranean IMAM 2017, Lisbon, Portugal, 2017.

[11] S. Sezen, A. Dogrul, C. Delen, and S. Bal, "Investigation of self-propulsion of DARPA Suboff by RANS method," Ocean Eng., vol. 150, pp. 258-271, 2018.

[12] S. Wilson-Haffenden, M. Renilson, D. Ranmuthugala, and E. Dawson, "An investigation into the wavemaking resistance of a submarine travelling below the free surface," presented at the International Maritime Conference 2010: Maritime Industry - Challenges, Opportunities and Imperatives, Sydney, Australia, 2010, p. 495.

[13] E. Dawson, "An investigation into the effects of submergence depth, speed and hull length-to-diameter ratio on the near surface operation of conventional submarines," PhD Thesis, University of Tasmania, 2014.

[14] A. Nematollahi, A. Dadvand, and M. Dawoodian, "An axisymmetric underwater vehicle-free surface interaction: A numerical study," Ocean Eng., vol. 96, pp. 205-214, Mar. 2015.

[15] A. Vali, B. Saranjam, and R. Kamali, "Experimental and numerical study of a submarine and propeller behaviors in submergence and surface conditions," J. Appl. Fluid Mech., vol.11, no. 5, pp. 12971308, 2018.

[16] M. M. Amiri, P. T. Esperança, M. A. Vitola, and S. H. Sphaier, "How does the free surface affect the hydrodynamics of a shallowly submerged submarine?," Appl. Ocean Res., vol. 76, pp. 34-50, Jul. 2018. 
[17] S. K. Shariati and S. H. Mousavizadegan, "Identification of underwater vehicles using surface wave pattern," Appl. Ocean Res., vol. 78, pp. 281-289, Sep. 2018.

[18] D. C. Wilcox, Turbulence Modeling for CFD, 3rd edition. La Cãnada, Calif.: D C W Industries, 2006.

[19] L. F. Richardson, "The Approximate Arithmetical Solution by Finite Differences of Physical Problems Involving Differential Equations, with an Application to the Stresses in a Masonry Dam," Philos. Trans. R. Soc. Lond. Ser. Contain. Pap. Math. Phys. Character, vol. 210, pp. 307-357, 1911.

[20] ITTC, "7.5-03-01-04 CFD, General CFD Verification," in ITTC - Recommended Procedures and Guidelines, 2011.

[21] P. J. Roache, "Verification of Codes and Calculations," AIAA J., vol. 36, no. 5, pp. 696-702, 1998.

[22] Ishmail. B. Celik, U. Ghia, and P. J. Roache, "Procedure for estimation and reporting of uncertainty due to discretization in CFD applications," J. Fluids Eng.-Trans. ASME, vol. 130, no. 7, Jul. 2008.

[23] F. Stern, R. V. Wilson, H. W. Coleman, and E. G. Paterson, "Comprehensive Approach to Verification and Validation of CFD Simulations-Part 1: Methodology and Procedures," J. Fluids Eng., vol. 123, no. 4, pp. 793-802, Jul. 2001.

[24] T. Tezdogan, Y. K. Demirel, P. Kellett, M. Khorasanchi, A. Incecik, and 0. Turan, "Full-scale unsteady RANS CFD simulations of ship behaviour and performance in head seas due to slow steaming," Ocean Eng., vol. 97, pp. 186206, Mar. 2015.

[25] F. Stern, R. Wilson, and J. Shao, "Quantitative V\&V of CFD simulations and certification of CFD codes," Int. J. Numer. Methods Fluids, vol. 50, no. 11, pp. 1335-1355, Apr. 2006.
[26] ITTC, "Practical guidelines for ship CFD applications," presented at the Proceedings of 26th ITTC, Hague, 2011.

[27] J. C. Date and S. R. Turnock, "A study into the techniques needed to accurately predict skin friction using RANS solvers with validation against Froude's historical flat plate experimental data," 1999. [Online]. Available: http://eprints.soton. ac.uk/46061/. [Accessed: 28-Aug2015].

[28] CD-adapco, "STAR CCM+ Documentation." 2015.

[29] A. Quérard, P. Temarel, and S. R. Turnock, "Influence of Viscous Effects on the Hydrodynamics of Ship-Like Sections Undergoing Symmetric and Anti-Symmetric Motions, Using RANS," pp. 683-692, Jan. 2008.

[30] T.-L. Liu and Z.-M. Guo, "Analysis of wave spectrum for submerged bodies moving near the free surface," Ocean Eng., vol. 58, pp. 239-251, Jan. 2013.

[31] S. K. Shariati and S. H. Mousavizadegan, "The effect of appendages on the hydrodynamic characteristics of an underwater vehicle near the free surface," Appl. Ocean Res., vol. 67, pp. 31-43, Sep. 2017.

[32] ITTC, "Report of Resistance Committee," presented at the Proceedings of 8th ITTC, Madrid, 1957.

[33] V. Bertram, Practical Ship Hydrodynamics, 2nd ed. Elsevier Science, 2014. 